\title{
The Correlates and Course of Depression in Patients with Lacunar Stroke: Results from the Secondary Prevention of Small Subcortical Strokes (SPS3) Study
}

\author{
Carole L. White $^{a, 1}$ Leslie A. McClure ${ }^{b, 2}$ Patricia M. Wallace Janet Braimah $^{d}$ \\ Alice Liskay ${ }^{\mathrm{e}}$ Ana Roldan ${ }^{\mathrm{f}, 1}$ Oscar R. Benavente ${ }^{\mathrm{g}, 1}$ for the SPS3 Investigators \\ ${ }^{a}$ School of Nursing, University of Texas Health Science Center at San Antonio, San Antonio, Tex., b Department \\ of Biostatistics, University of Alabama at Birmingham, Birmingham, Ala., 'Department of Neurology, Rochester \\ General Hospital, Rochester, N.Y., ${ }^{d}$ Department of Neurology, Grady Hospital, Atlanta, Ga., and ${ }^{\text {e MetroHealth }}$ \\ Medical Center, Center for Health Care Research and Policy, Cleveland, Ohio, USA; ${ }^{f}$ SPS3 Coordinating Center, \\ University of British Columbia, and ${ }^{9}$ Division of Neurology, Department of Medicine, Brain Research Center, \\ University of British Columbia, Vancouver, B.C., Canada
}

\section{Key Words}

Lacunar stroke $\cdot$ Depression after stroke $\cdot$ Predictors of outcome $\cdot$ Longitudinal study $\cdot$ Secondary Prevention of Small Subcortical Strokes study

\begin{abstract}
Background: Little is known about post-stroke depression in patients with lacunar stroke due to cerebral small vessel disease. Our objectives were to describe the prevalence of depression, its correlates and to examine the course of depression over time in a cohort of patients with lacunar stroke, the majority of whom had mild functional disability. Methods: Depression was determined in participants in the international Secondary Prevention of Small Subcortical Strokes (SPS3) trial which is testing antiplatelet therapies and targets of blood pressure control in patients with lacunar strokes and assessing stroke recurrence and cognitive decline. Depression was evaluated using the Patient Health Questionnaire. Multivariable logistic regression models were fitted to examine the relationship between the covariates of interest and depression. Generalized estimating equations were used to examine the likelihood of depression over time,
\end{abstract}

while accounting for the multiple measurements within each subject. Results: The prevalence of depression in 2,477 participants at approximately 4 months after stroke was $19 \%$. Older age (OR $0.97 ; 95 \% \mathrm{Cl} 0.96-0.99$ ), male gender (OR $0.62 ; 95 \% \mathrm{Cl} 0.48-0.80)$ and less cognitive impairment (OR $0.99 ; 95 \% \mathrm{Cl} 0.98-1.00)$ were independently associated with a lower risk of depression. Functional disability (OR 1.8; 95\% Cl 1.3-2.4), living with a spouse/family (OR 1.6; 95\% Cl 1.1-2.3) and risk factors for stroke (OR 1.2; 95\% Cl 1.0-1.3) were each independently associated with a higher risk of depression. Longitudinal modeling indicated that the likelihood of depression decreased by 1.12 times $(95 \% \mathrm{Cl} 1.06-1.17)$ for each 1 -year increase in time. Conclusions: One fifth of those in the SPS3 trial cohort reported depression that is sustained over time. Although this is lower than the prevalence reported for stroke in general, these results underscore the importance of early screening for post-stroke depression, treatment and follow-up to minimize the negative consequences associated with depression.

Copyright $\odot 2011$ S. Karger AG, Basel

SPS3 Coordinating Center.

SPS3 Statistical Center.

\section{KARGER}

두 2011 S. Karger AG, Basel

Fax +41613061234 E-Mail karger@karger.ch www.karger.com
Accessible online at: www.karger.com/ced
Carole L. White, $\mathrm{RN}, \mathrm{PhD}$

SPS3 Coordinating Center, 8300 Floyd Curl Drive - MSC 7883

University of Texas Health Science Center at San Antonio

San Antonio, TX 78229-3900 (USA)

Tel. +1 210567 5831,E-Mail whitec2@uthscsa.edu 


\section{Introduction}

Depression is a serious problem after stroke related both to its prevalence and to the adverse consequences associated with depression. A recent systematic review of observational studies reported a pooled estimate of prevalence of 33\% post-stroke depression (PSD; 95\% CI 2936) [1]. PSD is associated with fewer gains in rehabilitation and worse functional outcome [2,3], and even up to 4 years after stroke, depressed stroke survivors report restrictions in social roles and daily activities compared to non-depressed stroke survivors [4]. Depression after stroke is associated with a lower quality of life [5-8] and also with a higher risk of dying $[9,10]$. Information on the course of PSD is limited as many studies examining depression are cross-sectional with large variability across studies in the time interval between stroke and the assessment of depression $[1,11-14]$. Only a few studies have examined depression longitudinally [15-18] and most are limited to 1 year after stroke [18].

Lacunar stroke has been regarded as a relatively benign stroke subtype, in part related to the low prevalence of disability $[19,20]$, and thus, there is limited information regarding outcomes such as depression in this stroke subgroup. A recent study examining PSD in 127 patients with small subcortical infarcts reported an overall prevalence of depression of $35 \%$, similar to that reported for all stroke cases [21]. Stratifying patients by etiology of stroke (large artery disease or small vessel disease), the prevalence of depression in those with large artery disease was $52 \%$ and in those with small vessel disease $25 \%$. Although functional disability at 3 months predicted depression in the univariate model, only etiological type (large artery disease vs. small vessel disease) was significant in the multivariable model, with those with large artery disease being 3.2 times more likely (95\% CI 1.507.07) to be depressed compared to those with small vessel disease.

Investigating depression in those with lacunar stroke is important to better understand the consequences of stroke for this understudied group. It may also further our understanding of factors which are contributing to PSD, in addition to functional disability. Our objectives were to determine the prevalence of PSD in a cohort of lacunar stroke patients, to identify factors associated with PSD, and to describe the course of PSD in the 4 years after the acute event.

\section{Methods}

\section{Study Participants}

This study is utilizing data from the Secondary Prevention of Small Subcortical Strokes (SPS3) study which has been described elsewhere [22]. In brief, SPS3 is an ongoing international National Institutes of Health-funded trial with the objective of defining efficacious therapies for prevention of stroke recurrence and cognitive decline in patients with recent symptomatic small subcortical stroke. Participants with symptomatic, MRI-proven lacunar stroke within 6 months and no evidence of prior cortical stroke, significant ipsilateral carotid stenosis $(\geq 50 \%)$, or of a major cardioembolic source (intended to focus on lacunar infarcts due to cerebral small vessel disease) are eligible to participate. In a $2 \times 2$ factorial design, patients are randomly assigned to aspirin plus clopidogrel versus aspirin alone and to one of two targets of systolic blood pressure control (<130 vs. $130-149 \mathrm{~mm} \mathrm{Hg}$ ). Patients will be followed, on average, 4 years to ascertain outcome events. The sample for these analyses is comprised of all participants recruited through June $2010(\mathrm{n}=2,477)$, with a mean follow-up of 2.1 years. The SPS3 study has been approved by the institutional review boards at each participating institution and all participants have provided written consent for participation.

\section{Measurement}

Patients can be entered into the trial between 2 weeks and 6 months after the index stroke. Data collected at baseline include demographic information, medical history, specifically focusing on vascular risk factors, and functional status. For purposes of the analyses, the presence of any of the following was included in the composite variable of vascular risk factors: hypertension, diabetes, coronary artery disease, and hyperlipidemia. Patients are classified as normotensive (blood pressure $<130 / 80 \mathrm{~mm} \mathrm{Hg}$ ) or hypertensive, based on measured blood pressure at entry to trial, adjusted for the current number of antihypertensive medications. Patients are classified as diabetic, based on self-report or if prescribed antiglycemic medications within the initial 3 months of study entry. All currently prescribed medications including antidepressant medications are recorded at baseline and are updated during regular quarterly visits. Information is recorded as yes/no to classifications of tricyclic antidepressants and selective serotonin reuptake inhibitors. Data on the indication for these medications are not available, but it was assumed that they were prescribed for their primary indication of depression.

Depression is assessed with the Patient Health Questionnaire (PHQ)-9 [23], a 9-item scale that assesses the 9 Diagnostic and Statistical Manual of Mental Disorders (DSM-IV) depression criteria, at baseline and at each annual clinic visit. The patients rate each item for frequency of occurrence during the previous 2 weeks ( 0 - 'not at all', 1 - 'several days', 2 - 'more than half the days', 3 - 'nearly every day'). Current depression is defined when at least 2 of the 9 symptoms, including the anhedonia or depressed mood item, are endorsed as occurring more than half of the days [23]. In a study with stroke survivors [24], the PHQ-9 scores discriminated well between subjects with any versus no depressive disorder, with an area under the curve of 0.96. The PHQ-9 is an appropriate tool to measure depression in an international trial as it has been validated in both French and Spanish and has been found to be an effective measure for detecting depression in di- 
verse populations [25], including primary care patients in Latin America [26].

The Cognitive Abilities Screening Instrument (CASI) [27] is a screening measure for dementia with scores ranging from 0 to 100 , with 100 indicating good cognitive function $[27,28]$. We used the baseline CASI score to examine the association between cognitive function and depression.

Functional status is evaluated using the Barthel Index [29], a checklist of basic activities of living ranging from 0 (completely dependent) to 100 (completely independent). Handicap is rated using the modified Rankin Scale ranging from 0 (no symptoms) to 5 (severe disability) [30,31]. The Barthel Index and the Rankin Scale are both collected at baseline.

All patients undergo MRI prior to entry to the trial. The side and the location of the stroke as well as single versus multiple lacunes were examined for their relationship with depression.

\section{Data Analysis}

Patient characteristics at baseline overall and stratified by depression status were assessed as mean (standard deviation) or counts (\%), as appropriate. Logistic regression was used to assess the relationship between PSD and time since the qualifying stroke, stroke severity, gender, age, educational level, ethnicity, marital status, living arrangements, previous history of subcortical stroke, vascular risk factors, anti-hypertensive medications, diabetes, location of the strokes, and baseline cognitive functioning. Given the correlation between several of the variables, the univariate relationships were examined to determine which variables to include in the multivariable model. Only those variables that were significant in the univariate model at the 0.10 level were included in the multivariable models. Because of the variability in time of the baseline assessment among participants, all models were adjusted for time between the index stroke and the baseline assessment.

To examine the course of depression over time, analyses were restricted only to those who have a baseline depression score. Analyses proceeded by first examining the frequency of depression at each of the time points. Then, generalized estimating equations were used to examine the likelihood of depression over time, while accounting for the multiple measurements within each subject. Models accounted for factors that were associated with depression at baseline: time, age at qualifying stroke, time between qualifying stroke and the baseline depression scale, diabetes, gender, race (white vs. non-white), and Rankin Scale score (0-1 compared to $>1$ ). Time was examined to determine whether a linear effect was appropriate. Based on trends observed in the data, a compound symmetric covariance structure was utilized, allowing the correlation between measurements to vary as a function of the time between the measurements. Interactions were examined between time and diabetes, and between time and the Rankin Scale category, in order to assess whether the trends over time differed as a function of either diabetes or Rankin Scale category.

\section{Results}

The majority had made a good functional recovery at study entry with a median modified Rankin score of 1 . At the time of the initial assessment for depression (approx- imately 4 months after index lacunar stroke), 478 (19\%) of the 2,477 participants were classified as depressed. As can be seen in table 1, those who were depressed were younger, more likely to be female, and less likely to be white. Depressed participants were more likely to be living with a spouse or family than alone. Those classified as depressed at baseline also scored significantly lower on the baseline assessment of cognition. Of those classified as depressed, $46 \%$ were moderately disabled (Rankin score of 2-3) compared to $30 \%$ who were not depressed. There was a significantly higher percentage of diabetes and a higher number, on average, of cerebrovascular risk factors in the group who was depressed. There were no differences between the groups in location of stroke, side of stroke, or number of small subcortical infarcts.

At baseline, 351 patients (14\%) reported that they were currently taking antidepressant medications, either tricyclic antidepressants or selective serotonin reuptake inhibitors and over half reported continuation of these medications at all annual follow-up visits. Of those treated with antidepressants at baseline, $34 \%$ (118 of 351) were classified as depressed. Of those classified as depressed, $25 \%$ reported taking an antidepressant while $12 \%$ of participants who were classified as 'not depressed' reported taking an antidepressant (data not shown).

\section{Correlates of Depression at Baseline}

Table 2 shows the results from the unadjusted and the adjusted baseline logistic regression models. Age, gender, living with a spouse or family, functional disability, baseline cognitive status, and vascular risk factors for stroke each showed independent, significant associations with depression in the fully adjusted model. For each 1-year increase in age, the odds of depression decreased by approximately 0.97 times (95\% CI 0.96-0.99). Male stroke survivors were about $40 \%$ less likely to be classified as depressed compared to female stroke survivors (OR 0.62; $95 \%$ CI $0.48-0.80$ ). Those living with a spouse or family were 1.6 times (95\% CI 1.1-2.3) more likely to exhibit depressive symptoms as compared to those not living with family. Additionally, those with a Rankin score of 2-3 were 1.8 times (95\% CI 1.3-2.4) more likely to exhibit depressive symptoms, as compared to those with a Rankin score of $0-1$. Similarly, depression was associated with activities of daily living as measured by the Barthel Index. For each point increase in the Barthel Index, the odds of depression decreased by 0.99 (95\% CI 0.98-1.0). Depression was also associated with baseline cognitive function, with those scoring higher on the CASI less likely to be depressed (OR 0.99; 95\% CI 0.98-1.0). Finally, with each 
Table 1. Baseline descriptive statistics for all subjects and by depression status

\begin{tabular}{llll}
\hline All & Not \\
subjects & $\begin{array}{l}\text { depressed } \\
(81 \%)\end{array}$ & $\begin{array}{l}\text { Depressed } \\
(19 \%)\end{array}$ \\
\hline
\end{tabular}

Age at qualifying stroke ${ }^{1}$, years

Male $^{1}, \%$

Education $\leq$ high school, $\%$

Race $^{1}, \%$

Hispanic

White

Black

Other/mixed

Marital status, \%

Married

Divorced

Never married

Widowed

Living with spouse/

family ${ }^{1}, \%$

Barthel Index ${ }^{1}$

Rankin score 2-3 (moderate disability) ${ }^{1}, \%$

CASI $^{1}$

Prior symptomatic subcortical stroke, $\%$

Diabetic ${ }^{1}, \%$

History of hypertension, $\% \quad 76$

Adjusted SBP

category $^{1,2}, \%$

$<130 \mathrm{~mm} \mathrm{Hg}$

130-139 mm Hg

140-149 mm Hg

$\geq 150 \mathrm{~mm} \mathrm{Hg}$

Number of antihypertensive medications (capped at 4)

Number of vascular risk factors $^{1}$

Left-sided lesion, \%

Location of stroke, \%

Basal ganglia/internal capsule

Thalamus

Brainstem

Multiple lacunar infarcts, \%

Time between index stroke and baseline depression assessment, days

$128 \pm 68$

$\begin{array}{rrr}4 & 4 & 5 \\ 26 & 25 & 27 \\ 36 & 37 & 30 \\ 35 & 34 & 39\end{array}$

$$
1.7 \pm 1.1 \quad 1.7 \pm 1.1 \quad 1.7 \pm 1.2
$$$$
1.7 \pm 1.0 \quad 1.6 \pm 1.0 \quad 1.8 \pm 1.0
$$$$
54 \quad 54 \quad 57
$$

$\begin{array}{rrr}51 & 52 & 48 \\ 23 & 23 & 23 \\ 26 & 25 & 28 \\ 5 & 4 & 5\end{array}$

Data represent means \pm SD unless otherwise indicated. Related to missing data, sample size differs by variable. $\mathrm{CASI}=\mathrm{Cog}$ nitive Abilities Screening Instrument; SBP = systolic blood pressure.

${ }^{1} \mathrm{p}<0.05$ for comparison between the groups 'not depressed' and 'depressed'. ${ }^{2}$ Adjusted for number of antihypertensive medications taken at baseline.
Table 2. Results of the logistic regression models (odds ratios and 95\% CIs)

\begin{tabular}{|c|c|c|}
\hline & $\begin{array}{l}\text { Univariate } \\
\text { model }\end{array}$ & $\begin{array}{l}\text { Multivariable } \\
\text { model }^{1}\end{array}$ \\
\hline \multicolumn{3}{|l|}{ Age at qualifying stroke, } \\
\hline Male & $0.68(0.55-0.83)$ & $0.62(0.48-0.80)$ \\
\hline Education $\leq$ high school & $1.1(0.92-1.4)$ & - \\
\hline \multicolumn{3}{|l|}{ Race } \\
\hline White & REF & - \\
\hline Black & $1.6(1.2-2.1)$ & - \\
\hline Hispanic & $1.2(0.99-1.6)$ & - \\
\hline Other/mixed & $0.98(0.52-1.9)$ & - \\
\hline Race (non-white) & $1.3(1.1-1.6)$ & $1.1(0.84-1.5)$ \\
\hline \multicolumn{3}{|l|}{ Marital status } \\
\hline Married & REF & - \\
\hline Divorced & $0.90(0.63-1.3)$ & - \\
\hline Never married & $1.2(0.75-1.8)$ & - \\
\hline Widowed & $1.0(0.72-1.5)$ & - \\
\hline Living with spouse/family & $1.7(1.2-2.4)$ & $1.6(1.1-2.3)$ \\
\hline Barthel Index & $0.98(0.97-0.99)$ & $0.99(0.98-1.0)$ \\
\hline \multicolumn{3}{|l|}{ Rankin scale $2-3$} \\
\hline (moderate disability) & $2.1(1.7-2.5)$ & $1.8(1.3-2.4)$ \\
\hline CASI & $0.99(0.98-1.00)$ & $0.99(0.98-1.0)$ \\
\hline Prior subcortical stroke & $1.2(0.86-1.7)$ & - \\
\hline Diabetes (self-report) & $1.6(1.3-1.9)$ & - \\
\hline History of hypertension & $1.2(0.97-1.6)$ & - \\
\hline \multicolumn{3}{|l|}{ Adjusted SBP category ${ }^{2}$} \\
\hline$<130 \mathrm{~mm} \mathrm{Hg}$ & REF & - \\
\hline $130-139$ mm Hg & $0.87(0.52-1.5)$ & - \\
\hline $140-149 \mathrm{~mm} \mathrm{Hg}$ & $0.67(0.40-1.1)$ & - \\
\hline$\geq 150 \mathrm{~mm} \mathrm{Hg}$ & $0.95(0.58-1.6)$ & - \\
\hline $\begin{array}{l}\text { Number of antihyper- } \\
\text { tensive medications }\end{array}$ & & - \\
\hline (capped at 4) & $1.1(0.96-1.1)$ & \\
\hline \multicolumn{3}{|l|}{ Number of vascular risk } \\
\hline factors & $1.2(1.1-1.3)$ & $1.2(1.0-1.3)$ \\
\hline Left-sided lesion & $1.2(0.93-1.5)$ & - \\
\hline \multicolumn{3}{|l|}{ Location of stroke } \\
\hline Thalamus & REF & - \\
\hline $\begin{array}{l}\text { Basal ganglia/internal } \\
\text { capsule }\end{array}$ & $0.91(0.71-1.2)$ & - \\
\hline Brainstem & $1.1(0.84-1.5)$ & - \\
\hline Multiple lacunar infarcts & $1.2(0.67-2.3)$ & - \\
\hline
\end{tabular}

CASI = Cognitive Abilities Screening Instrument; SBP = systolic blood pressure.

${ }^{1}$ Only includes covariates significant in the univariate model at the 0.10 level; adjusted for time between qualifying stroke and 3-month follow-up.

${ }^{2}$ Adjusted for number of antihypertensive medications taken at baseline. 
increase in number of vascular risk factors, the odds of depression increased by 1.2 (95\% CI 1.0-1.3).

\section{Longitudinal Course of Depression}

Analyses were performed on 2,477 patients. Patients were included even if they were missing an intermediate visit, as long as the baseline observation was present. There were 2,477 observations at baseline, 1,934 observations at year 1, 1,468 observations at year 2, 1,117 observations at year 3 , and 714 observations at year 4 . There was a decrease in the prevalence of depression over the 4 years following stroke with a prevalence of $19 \%$ at baseline, $17 \%$ at year $1,16 \%$ at years 2 and 3 , and $13 \%$ at year 4. While there were various patterns in the trajectory of depression for this cohort, $31 \%$ of the cohort reported depression at least once during the follow-up. There was a small number $(n=28,1 \%)$ who remained depressed over the course of the follow-up period. This group had a significantly lower baseline CASI score, a more severe stroke (Rankin score 2-3), a higher number of stroke risk factors, were prescribed a higher number of antihypertensive medications at baseline and were more likely to be taking antidepressant medication at baseline. However, among those who were classified as depressed at all follow-ups, only $19 \%$ reported being on anti-depressant medications at all annual visits, and almost $50 \%$ reported not being on anti-depressant medications at any of their annual visits.

In generalized estimating equation modeling, the interactions between time and diabetes and between time and the Rankin score were nonsignificant $(\mathrm{p}=0.25$ and 0.83 , respectively), and thus, were excluded from further modeling. After adjustment for age at qualifying stroke, time between the qualifying stroke and the baseline follow-up, diabetes, sex and race, the likelihood of depression decreases by 1.12 times (95\% CI 1.06-1.17) for each 1 -year increase in time.

\section{Discussion}

This study is unique in its examination of the correlates and the course of depression in a cohort of those with lacunar stroke. A key question concerns the similarities and differences in PSD in those with lacunar stroke compared to other stroke subtypes. Although location and side of lesion have been studied frequently [32, 33], the examination of stroke subtype in PSD has been limited. The Depression after Stroke (DESTRO) study evaluated stroke subtype as a risk factor for PSD [34]. Cat- egorizing strokes according to the Oxfordshire Community Stroke Project classification [35], they reported a similar incidence of PSD for each of the ischemic subtypes (approximately 33\%) except for total anterior circulation infarcts which showed a significantly higher incidence (47.9\%). In contrast, two recent studies which examined stroke subtype and PSD did not find significant differences by stroke subtype [36, 37].

The prevalence of depression in the SPS3 cohort was $19 \%$ at baseline (approximately 4 months after stroke), much lower than the $33 \%$ pooled estimate of depression reported by Hackett et al. [1]. There may be several reasons for this difference, unrelated to stroke subtype. First, there is significant variation across studies in the reported prevalence of depression (14-41\%) depending on the method or measure to assess depression [1]. Second, the SPS3 cohort was comprised of mostly mild stroke, related to exclusion of those with severe deficits by SPS3 protocol and the favorable outcome for the majority of participants (median Rankin score of 1). Several recent studies with cohorts similar to SPS3 in terms of functional recovery have reported estimates of depression prevalence at 2-3 months after stroke comparable to that reported in SPS3 $[36,38]$. In a cohort of 127 patients with small subcortical infarcts, Chen et al. [21] reported a prevalence of $25 \%$ for those with small subcortical stroke with an etiology presumed to be small vessel disease [21]. The authors of the DESTRO study suggested that the higher incidence of depression found in patients with total anterior circulation infarct may be related to the size of the lesion and also the severe disability, both characteristic of this stroke subtype [34]. In the same vein, the lower prevalence found in SPS3 may be related to the smaller lesion size $(\leq 2.0$ $\mathrm{cm}$ ) and the short-term favorable outcomes compared to other stroke subtypes [39], although not possible to conclude with certainty in the absence of a control group.

A strength of this study is the 4-year assessment of depression in a large number of people, with results showing that the prevalence of depression decreased by only about $10 \%$ for each subsequent year after stroke. While only a small percentage of patients reported depression at each follow-up, overall, one third of the cohort reported depression at least once during follow-up, highlighting its significance after stroke. The prevalence of hypertension and diabetes are high in this cohort and we observed an association between an increasing number of vascular risk factors and PSD at approximately 4 months after stroke. The predictors of late-onset depression may relate to the ongoing cerebral small vessel disease process despite the SPS3 intervention therapy. In a case-control 
study of mood after stroke, the results indicated that vascular factors were also important in late-onset PSD, measured at approximately 9 months after stroke [40]. Although conditions such as hypertension and diabetes have been associated with depression in the general population [41, 42], little attention has been given to their role in PSD. This warrants further study.

That patients who reported living with a spouse/family were 1.6 times more likely to be classified as depressed compared to those living alone/in an assisted living facility seems counterintuitive, as generally, family support is found to be protective against adverse outcomes such as depression [43]. Family expectations regarding recovery and the patient's return to previous roles can influence the stroke survivor's emotional state when the stroke survivor feels unable to return to previous roles, despite seemingly normal physical ability $[44,45]$. It may be this mismatch between family and stroke survivor expectations that is contributing to this association. This may also be a spurious finding as living in the same household may not necessarily be perceived as supportive but rather the quality of the relationship.

A potential limitation of this study is the inherent differences between participants in a clinical trial and the general population of stroke survivors. The fact that these individuals have agreed to participate in a clinical trial may suggest different emotional and behavioral characteristics which may impact the generalizability of our results concerning depression. However, our prevalence estimates were similar to those previously reported for mild stroke [36] as well as for the identified correlates of PSD, suggesting that these results may be generalizable to those with lacunar stroke beyond a clinical trial. Another limitation is the lack of information on the history of depression prior to the stroke. Without this information we are unable to adjust for this potential confounding variable in the multivariable models.

The World Health Organization now recognizes depression as one of the most burdensome diseases worldwide [46]. One fifth of those with lacunar stroke reported symptoms consistent with depression in the first year following stroke, which is about $50 \%$ higher than the prevalence of symptoms of major or minor depression reported in several population-based surveys [11, 47, 48]. The available data suggest that PSD remains frequently undertreated $[49,50]$. Only $25 \%$ of depressed individuals in the present study were taking antidepressants, similar to the findings from studies conducted in Sweden [51] and Australia [13]. It is critical that all stroke survivors are screened early for depression and are provided with appropriate treatment and follow-up to ensure adequacy of the treatment. The follow-up is particularly warranted given the little average change in depression frequency observed in this cohort over time.

\section{Acknowledgment}

SPS3 is an investigator-initiated study funded by a cooperative agreement from the National Institute of Neurological Disorders and Stroke of the United States (grant No. 2 U01 NS38529-04A1).

\section{References}

1 Hackett ML, Yapa C, Parag V, Anderson CS: Frequency of depression after stroke: a systematic review of observational studies. Stroke 2005;36:1330-1340.

2 Herrmann N, Black SE, Lawrence J, Szekely C, Szalai JP: The Sunnybrook Stroke Study: a prospective study of depressive symptoms and functional outcome. Stroke 1998;29: 618-624.

-3 Pohjasvaara T, Vataja R, Leppavuori A, Kaste M, Erkinjuntti T: Depression is an independent predictor of poor long-term functional outcome post-stroke. Eur J Neurol 2001;8: 315-319.

4 Desrosiers J, Noreau L, Rochette A, Bourbonnais D, Bravo G, Bourget A: Predictors of long-term participation after stroke. Disabil Rehabil 2006;28:221-230.

\footnotetext{
5 Carod-Artal J, Egido JA, Gonzalez JL, Varela de Seijas E: Quality of life among stroke survivors evaluated 1 year after stroke: experience of a stroke unit. Stroke 2000;31:2995-3000.

6 King RB: Quality of life after stroke. Stroke 1996;27:1467-1472.

7 Kwok T, Lo RS, Wong E, Wai-Kwong T, Mok V, Kai-Sing W: Quality of life of stroke survivors: a 1-year follow-up study. Arch Phys Med Rehabil 2006;87:1177-1182.

8 Pan JH, Song XY, Lee SY, Kwok T: Longitudinal analysis of quality of life for stroke survivors using latent curve models. Stroke 2008;39:2795-2802.

9 Morris PL, Robinson RG, Andrzejewski P, Samuels J, Price TR: Association of depression with 10-year poststroke mortality. Am J Psychiatry 1993;150:124-129.
}

10 Williams LS, Ghose SS, Swindle RW: Depression and other mental health diagnoses increase mortality risk after ischemic stroke. Am J Psychiatry 2004;161:1090-1095.

11 Beekman AT, Penninx BW, Deeg DJ, Ormel J, Smit JH, Braam AW, van Tilburg W: Depression in survivors of stroke: a community-based study of prevalence, risk factors and consequences. Soc Psychiatry Psychiatr Epidemiol 1998;33:463-470.

12 Desmond DW, Remien RH, Moroney JT, Stern Y, Sano M, Williams JB: Ischemic stroke and depression. J Int Neuropsychol Soc 2003;9:429-439.

13 Paul SL, Dewey HM, Sturm JW, Macdonell RA, Thrift AG: Prevalence of depression and use of antidepressant medication at 5-years poststroke in the North East Melbourne Stroke Incidence Study. Stroke 2006;37: 2854-2855. 
14 Williams LS, Weinberger M, Harris LE, Biller J: Measuring quality of life in a way that is meaningful to stroke patients. Neurology 1999;53:1839-1843.

15 Aben I, Verhey F, Strik J, Lousberg R, Lodder J, Honig A: A comparative study into the one year cumulative incidence of depression after stroke and myocardial infarction. J Neurol Neurosurg Psychiatry 2003;74:581-585.

-16 Andersen G, Vestergaard K, Riis J, Lauritzen L: Incidence of post-stroke depression during the first year in a large unselected stroke population determined using a valid standardized rating scale. Acta Psychiatr Scand 1994;90:190-195.

-17 Kauhanen M, Korpelainen JT, Hiltunen P, Brusin E, Mononen H, Maatta R, Nieminen P, Sotaniemi KA, Myllyla VV: Poststroke depression correlates with cognitive impairment and neurological deficits. Stroke 1999; 30:1875-1880.

-18 Paolucci S, Gandolfo C, Provinciali L, Torta $\mathrm{R}$, Toso V; on the behalf of the DESTRO Study Group: The Italian multicenter observational study on post-stroke depression (DESTRO). J Neurol 2006;253:556-562.

-19 Lawrence ES, Coshall C, Dundas R, Stewart J, Rudd AG, Howard R, Wolfe CD: Estimates of the prevalence of acute stroke impairments and disability in a multiethnic population. Stroke 2001;32:1279-1284.

-20 Samuelsson M, Soderfeldt B, Olsson GB: Functional outcome in patients with lacunar infarction. Stroke 1996;27:842-846.

$\checkmark 21$ Chen Y, Chen X, Mok VCT, Lam WWM, Wong KS, Tang WK: Poststroke depression in patients with small subcortical infarcts. Clin Neurol Neurosurg 2009;111:256-260.

-22 Benavente OR, White CL, Pearce L, Pergola P, Roldan A, Benavente M-F, Coffey C, McClure LA, Szychowski JM, Conwit R, Heberling PA, Howard G, Bazan C, Vidal-Pergola G, Talbert R, Hart RG; for the SPS3 Investigators: The Secondary Prevention of Small Subcortical Strokes (SPS3) study. Int J Stroke 2011;6:164-175.

-23 Spitzer RL, Kroenke K, Williams JB: Validation and utility of a self-report version of PRIME-MD: the PHQ primary care study. JAMA 1999;282:1737-1744.

-24 Williams LS, Brizendine EJ, Plue L, Bakas T, Tu W, Hendrie H, Kroenke K: Performance of the PHQ-9 as a screening tool for depression after stroke. Stroke 2005;36:635-638.

-25 Huang FY, Chung H, Kroenke K, Delucchi KL, Spitzer RL: Using the Patient Health Questionnaire-9 to measure depression among racially and ethnically diverse primary care patients. J Gen Intern Med 2006; 21:547-552.
26 Wulsin L, Somoza E, Heck J: The feasibility of using the Spanish PHQ-9 to screen for depression in primary care in Honduras. Prim Care Companion J Clin Psychiatry 2002;4: 191-195.

27 Teng EL, Hasegawa K, Homma A, Imai Y, Larson E, Graves A, Sugimoto K, Yamaguchi T, Sasaki H, Chiu D, et al: The Cognitive Abilities Screening Instrument (CASI): a practical test for cross-cultural epidemiological studies of dementia. Int Psychogeriatr 1994;6:45-58.

28 McCurry SM, Edland SD, Teri L, Kukull WA Bowen JD, McCormick WC, Larson EB: The Cognitive Abilities Screening Instrument (CASI): data from a cohort of 2524 cognitively intact elderly. Int J Geriatr Psychiatry 1999; 14:882-888.

29 Mahoney FI, Barthel DW: Functional evaluation: the Barthel Index. Md State Med J 1965; 14:61-65.

30 Farrell B, Godwin J, Richards S, Warlow C: The United Kingdom transient ischaemic attack (UK-TIA) aspirin trial: final results. J Neurol Neurosurg Psychiatry 1991;54:10441054.

31 Rankin J: Cerebral vascular accidents in patients over the age of 60.2. Prognosis. Scott Med J 1957;2:200-215.

\$2 Carson AJ, MacHale S, Allen K, Lawrie SM, Dennis M, House A, Sharpe M: Depression after stroke and lesion location: a systematic review. Lancet 2000;356:122-126.

>33 Hackett ML, Anderson CS: Predictors of depression after stroke: a systematic review of observational studies. Stroke 2005;36:22962301.

34 Provinciali L, Paolucci S, Torta R, Toso V, Gobbi B, Gandolfo C: Depression after firstever ischemic stroke: the prognostic role of neuroanatomic subtypes in clinical practice. Cerebrovasc Dis 2008;26:592-599.

35 Bamford J, Sandercock P, Dennis M, Burn J, Warlow C: Classification and natural history of clinically identifiable subtypes of cerebral infarction. Lancet 1991;337:1521-1526.

-36 Snaphaan L, van der Werf S, Kanselaar K, de Leeuw FE: Post-stroke depressive symptoms are associated with post-stroke characteristics. Cerebrovasc Dis 2009;28:551-557. 37 Thomas SA, Lincoln NB: Predictors of emo-
tional distress after stroke. Stroke 2008;39: 1240-1245.

38 Schwab-Malek S, Vatankhah B, Bogdahn U, Horn M, Audebert HJ: Depressive symptoms and quality of life after thrombolysis in stroke: the TEMPiS study. J Neurol 2010;257: 1848-1854.
39 Norrving B: Long-term prognosis after lacunar infarction. Lancet Neurol 2003;2:238245.

40 Chatterjee K, Fall S, Barer D: Mood after stroke: a case control study of biochemical, neuro-imaging and socio-economic risk factors for major depression in stroke survivors. BMC Neurol 2010;10:125.

-41 Anderson RJ, Freedland KE, Clouse RE, Lustman PJ: The prevalence of comorbid depression in adults with diabetes: a metaanalysis. Diabetes Care 2001;24:1069-1078.

42 Hajjar I, Quach L, Yang F, Chaves PHM, Newman AB, Mukamal K, Longstreth W Jr, Inzitari M, Lipsitz LA: Hypertension, white matter hyperintensities, and concurrent impairments in mobility, cognition, and mood: the Cardiovascular Health Study. Circulation 2011;123:858-865.

43 Huang C-Y, Hsu M-C, Hsu S-P, Cheng P-C, Lin S-F, Chuang C-H: Mediating roles of social support on poststroke depression and quality of life in patients with ischemic stroke. J Clin Nurs 2010;19:2752-2762.

44 Barskova T, Wilz G: Interdependence of stroke survivors' recovery and their relatives' attitudes and health: a contribution to investigating the causal effects. Disabil Rehabil 2007;29:1481-1491.

45 Green TL, King KM: The trajectory of minor stroke recovery for men and their female spousal caregivers: literature review. J Adv Nurs 2007;58:517-531.

46 World Health Organization: The Global Burden of Disease 2004 Update. Geneva, Switzerland, 2008

47 Kroenke K, Strine TW, Spitzer RL, Williams JBW, Berry JT, Mokdad AH: The PHQ-8 as a measure of current depression in the general population. J Affect Disord 2009;114:163173.

-48 Steffens DC, Fisher GG, Langa KM, Potter GG, Plassman BL: Prevalence of depression among older Americans: the Aging, Demographics and Memory Study. Int Psychogeriatr 2009;21:879-888.

49 Gabaldon L, Fuentes B, Frank-Garcia A, Diez-Tejedor E: Poststroke depression: importance of its detection and treatment. Cerebrovasc Dis 2007;24:181-188.

50 Hart S, Morris R: Screening for depression after stroke: an exploration of professionals' compliance with guidelines. Clin Rehabil 2008;22:60-70.

51 Eriksson M, Asplund K, Glader EL, Norrving B, Stegmayr B, Terent A, Asberg KH, Wester PO, Riks-Stroke C: Self-reported depression and use of antidepressants after stroke: a national survey. Stroke 2004;35: 936-941. 